This paper is a post-print of an article published in Thesis Eleven 74(1) 2003:76-88. The definitive version is available at: http://the.sagepub.com/cgi/content/abstract/74/1/76

\title{
Simultanagnosia, Sense of Place and the Garden Idea
}

\section{Michael Crozier}

\begin{abstract}
A pervasive theme in George Seddon's extensive oeuvre is sense of place. Over a number of decades he has explored and reworked the conceptual and phenomenological aspects of this theme. This article takes its cue from Seddon's more recent critical observations on sense of place and considers the temporal and spatial dimensions of everyday experience in the informational age. Recent trends in gardening and garden theory are examined in the context of certain pathologies associated with this experience, and in particular cultural simultanagnosia: 'unable to see the forest for the trees'. A key argument is that as contemporary experience tends to differentiate into discrete modules there is paradoxically also a tendency to reengage with the ecocultural world in the form of place-making, in symbolic performances of milieu.
\end{abstract}

\section{KEYWORDS}

Garden theory, George Seddon, informational age, John Dixon Hunt, landscape architecture, place-making, sense of place, simultanagnosia

Places are easy to get on with if you meet them on their own terms. George Seddon (1997)

\section{INTRODUCTION}

George Seddon is an inveterate traveller. According to his mother, he was always restless. In the world at large, he is widely recognized as an expert on 'sense of place'. In an autobiographical moment Seddon has pondered why the concept of sense of place has continued to preoccupy him especially as a nomadic academic. He fields a variety of reasons for this ongoing fascination. The first is straightforward: it is symptomatic of a real concern with conservation. Equally, he suggests that it could be that his vagrant childhood bequeathed a hankering for 'place'. (In the margin he notes that this is perhaps the case of an unsettled culture more generally.) He also turns this hankering around and pronounces that 'travel can strengthen the sense of place'. The moment is reflective yet dynamic. As he muses, Seddon unfolds a traveller's tale of engagement and growing understanding through, in, and of different places. In the process, focus and focal range emerge as important themes in this life story, his life story (Seddon, 1997: 136-42).

Seddon warns that the idea of sense of place should be applied with caution. His worry arises from its appropriative proclivities: 'it can be a way of legitimising a set of personal and subjective evaluative criteria as if they had some externally derived authority' (1997: 106). More than this, he is troubled that while the sense of place has become an extremely popular idea, it is generally trumpeted with little analysis of the idea itself. Seddon does not exclude his own earlier work from this kind of conceptual naivety. He describes his use of the idea in the early 1970s as 'old fashioned regional geography' - an integrative approach that was distinct from the mainstream geography of the time. The reason he used the phrase 
'sense of place' was an endeavour to overcome the narrow scientific focus of this geography.

Seddon now readily admits that he 'assumed rather than analysed' the idea. Nonetheless he insists that we still need an integrating perspective, a 'sense of place.' What is required is that the idea be brought down to earth. We have to be more than aware that it is culturally bound and as such needs to be submitted to ongoing critical scrutiny in its application (Seddon, 1997: 105-6).

This article is interested in a critical sense of place in its conceptual and experiential moments. In the first instance this will be pursued through the lens of contemporary everyday experience. What are people's senses of place today? How does sense of place fare in the temporal and spatial dimensions of informational society? Identification of certain pathologies associated with this experience will form a bridge to the garden idea, taking a meander through Seddon's garden-making and beyond. A critical evaluation of the recent surge in garden theorization and gardening practice is then raised onto a higher anthropological level in order to generate a wider sociocultural perspective on the 'milieu' of contemporary culture. Seddon's engagement with place is taken as indicative of the creative potential of this milieu.

\section{EVERYDAY EXPERIENCE IN THE INFORMATIONAL AGE}

The dynamics of informational society are dramatically altering the constitutive structure of everyday experience. Among other things this involves the increasing role of information as the vital resource of society. It also entails the instrumental disaggregation of culture into commodities. The first links people into - and out of - diverse and distinct networks of connection (Castells, 2000; Van Dyjk, 1999; Wellman, 2001). The second offers the joys of the 'experience economy' where cultural resources are transformed into paid-for personal experiences, entertainments and lifestyle options (Rifkin, 2000). The older sense of inhabiting $a$ culture gives way to highly differentiated systems of time and space in which people now act and experience. Alberto Melucci gives an account of this shift in his study The Playing Self (1996), highlighting some of the key features of time and space in contemporary experience.

In contemporary society, everyday existence runs on various times, to the point where they are at odds with each other: measurable and immeasurable times; slow motion times and breathlessly-quick times; minute times and vast times. Everyday life is filled with a variety of different times, as rapid switching shuttles us back and forth through the disconnected, dissonant and atonal, waylaying continuity for flexibility, and demanding that we constantly refocus. We are thus required to flit from one specific temporal reference system to another, between the more intimate temporal realms and the various socially defined and regulated time systems. As a consequence, one of the central challenges of everyday life has become the negotiation of dissonance that arises as we traverse through these highly differentiated time systems.

Melucci argues, however, that the capacity for the human actor to constitute him- or herself in unity and continuity is nonetheless dependent on some kind of integration of differentiated time into a shared collective frame and within a personal biography. This is complicated by the fact that multiple time is also discontinuous time - a time in which independent histories unfold at the same time. As a result, past and future, memory and project become de-anchored in the collective present, leaving the human subject adrift in the particular time system of the moment. The paradox here is that the essential character of differentiated time is cultural, an artefact that is constituted within everyday social 
relationships. As Melucci notes, 'all the times of nature are [now] subject to social intervention which modifies them when it does not completely annihilate them' (1996: 16).

The other fundamental category of everyday human experience - space

- has also been dramatically transformed in informational society. In the past physical space was experienced in varying ways - metrically, associatively, figuratively, etc. - yet always with some palpable sense of preestablished dimensions and scale acquired through experience and comparison. This habitual space is now confronted with a radically different conception of space. On the one hand the new informational space is an abstract space of boundless expansion, accessed through the exponential developments in communication technologies. Yet, paradoxically, it is also a space of near limitless compression, embodied in the telos of miniaturization technology. In both instances there is no meaningful connection to the physical space of ordinary everyday life.

Consequently spatial relationships are disrupted in a number of ways. First, the new informational conception decouples the link between space and dimension. Vast quantities of data can now be stored on an infinitesimal point and transferred in a nanosecond, bearing no relation to the physical dimensions of the objects recorded and the physical distances involved. Second, the new informational space also destabilizes the relationship between proximity and distance. Virtual images are now generated that expose us to spaces utterly alien to our direct physical experience. A sense of global space is also now contracted into the routine data of everyday life, as is the domestication of long distance travel. Thus our daily lives are increasingly reoriented with the symbolic expansion and perceptual contraction of space.

In the process, notions of large and small, near and far, are no longer just palpable metrics but are now also symbolic indicators: 'cultural artefacts organizing a space' that is 'no less real than the physical space' (Melucci, 1996: 17). Like the category of time, space is now multiple and discontinuous, compelling us to position and reposition with agility and flexibility through diverse spatial systems. But this too brings new problems. Even with all the transformations we still habituate a physical space, handle concrete physical objects, and physically travel across telluric distances. The experience of constant movement through fluid space generates rootlessness and bewilderment, the preoccupation with movement itself often leading to an indifference to actual location or place.

However, this indifference is at odds with the very physicality of our bodies. In the extreme, what was once simply a taken-for-granted set of spatial skills now has to be learnt or relearnt (especially by the space cadets of cyberspace) in order to inhabit a body in physical space. This is a culturally induced phenomenon akin to the neuropsychological condition of topographagnosia - an abnormal inability to deal with spatial relationships in finding one's way around in extrapersonal space, or more simply, 'getting lost in the world' (Grüsser and Landis, 1991: 411-30).

The disjuncture between space and the physical body also applies to the contemporary experience of actual places. The new space as a multidimensional and open artefact may offer all sorts of experiential possibilities but it also runs the risk of creating the opposite. To the extent that all spatial experience becomes commensurate, physical locations are reduced to indistinct data for processing. Places are easily subsumed into a monotony of equivalent dimensions and the ever-the-same (Melucci, 1996: 18). In the 'experience economy', physical location is more often than not simply incidental to the pursuit of experiential intensity. The spatial world of infinite virtuality is also the homogenized terrain of theme park-ism.

The main point to be emphasized here is what Melucci observes as an unresolved tension that patterns daily life in the informational age. This tension strains between 'on the 
one hand, the dynamic impulse to continuously create the new space and contents of experience, and, on the other, the need to observe the natural confines of experience itself'. The phenomenon of planetary society suggests a global society that is 'totally interconnected by its capacity of intervening on its environment and on social life itself'. Nevertheless, it is a society that is still dependent on its natural home: planet Earth. And the rhythms of nature are imprinted in the physical dynamics of our biology, of our bodies. We may forget these natural metronomes but we cannot live without them (Melucci, 1996: 2).

\section{SIMULTANAGNOSIA}

Yet the malaise to note here is not amnesia per se. Rather, the discontinuity and dissonance Melucci detects in contemporary everyday experience can perhaps best be captured in the condition of simultanagnosia - the inability to perceive or to integrate stimuli presented simultaneously to different parts of the visual field, in short, a disturbance of overview. The neuropsychological condition refers to the inability to see more than one visual stimulus at a time, irrespective of its size, as well as the failure to grasp the whole while being able to recognize the parts. This type of agnosia or dysfunction is no doubt far more familiar when cast in the popular saying: "unable to see the wood (or forest) for the trees' (Grüsser and Landis, 1991: 215-17).

What if we translate this clinical condition into a category of cultural analysis, relating it to the temporal as well as the spatial? This would specify a cultural condition of simultanagnosia, arising as a means of coping with the differentiation of time, the multidimensionality of space, and the discontinuity of both, in contemporary life. The very real experience of the proliferation of 'action settings', coupled with information overload, leads to bracketing, and our integrative capacities tend to go into sleep mode. Paradoxically, however, the very means of coping then tends to reinforce the malaise it is seeking some relief from. The capacity to stand back and take an overview appears as all too difficult, if not impossible. Aside from anything else, pausing and reflecting at a distance also carries the threat of overwhelming complexity.

Contemporary high flyers seem to enjoy the symptoms of simultanagnosia, capitalizing on its pathologies. In this ether, corporate and managerial cowboys shoot through a world of pure movement at high speed enabling them to exercise power while leaving responsibility behind in place. Similarly, the incessant thrill seekers thrive on the prospect of infinite possibility, maintaining an eternal search for 'intensity of experience' with no sense of place. At more human altitudes, people struggle with identity issues in a world seemingly without edges or borders, yet riddled with dissonance. The capacity to make sense of one's life, of one's own life course, becomes problematic when it is experienced simply as a random series of disconnected events. The opportunities to negotiate the boundaries, the differences between self and other, are somewhat diminished, as the self first and foremost has to cope with finding and refinding bearings amid shifting contexts. The development of one's persona is thus complicated by the survival strategy of multiple personae (see Sennett, 2000).

At one extreme the archetype of cultural simultanagnosia is the person without qualities because he or she has so many discrete qualities. At another extreme is the retreat into a persona in which the self is rigidly structured by an exclusivist set of social rules that affirms a particular worldview and demonizes all others (see Castells, 2000: 23). This is the person without qualities of his or her own: the fundamentalist character of caricature. In both instances, the particular precludes overview. Most people, however, manage to navigate somewhere betwixt and between these extremes, even if with a good deal of 
trepidation.

The contemporary struggle for social recognition is thus confronted with the boundless possibilities offered by multiple action settings yet, simultaneously, debilitated to varying degrees by this world without edges. It is perhaps not all that surprising then that in the face of this dilemma, people find a certain solace in what is arguably a near universal human activity - place-making - especially in one of its most intense forms, gardening.

\section{THE GARDEN IDEA}

There is a gardening story told about 1930s Nazi Germany. Apparently there was a healthy trade in the sale of nursery stock at the time. However, some plants were far more popular than others. In particular, the sale of fast-growing plants far outnumbered that of slow-growing varieties. It would appear that the Nazis' takeover of power had not dampened the desire to pursue gardening pleasures. On the other hand, the run on fastgrowing plants was hardly a vote of confidence in the future: thousand-year reichs are surely stuff of elms not annuals. Perhaps there was an element of fashion involved but there is probably more to the explanation than this, given the context. The dramatic mobilization of the whole society by the Nazi state involved deliberate strategies to concentrate power and to incorporate the population through social atomization. Inculcating a sense of constant movement and insecurity was part and parcel of the regime's totalitarian project. The rhythms of gardening could no doubt steal some temporary relief, but garden-making could not be totally immunized from this onslaught. In this light, the gardening aspiration to view the whole - 'to see things through' - can be understood to have been tempered by the sense that 'tomorrow might very well not belong to me' or my garden. The old wisdom of 'it is best to plant to the times' undoubtedly rang true.

This story has a resonance with John Dixon Hunt's general observation that some of the most pronounced examples of invented garden traditions seem to appear in societies experiencing dramatic change (Hunt, 1991). The reorientation of the English garden from an inward to an outward prospect during the 18th century is a compelling example - and a key conceptual instrument - of a society coming to grips with a complex process of modernization (Hunt, 1986). In the previous century the power of gardening imagery was brutally illustrated by the levelling puritans' systematic destruction of the royal gardens and their treed avenues after the execution of Charles I in 1649 (Strong, 1979: 197). Perhaps a little less fraught and closer to the present, certain connections can be drawn between contemporary gardening trends and more recent social transformations, especially the new challenges of everyday experience outlined above.

There have been several notable developments in 'gardening' over recent years. Like numerous other cultural activities, gardening has become increasingly commodified in certain ways, though not all (see Seddon, 1997: 162). The array of plant variety and level of establishment has proliferated. A quick trip to the local nursery will find you a pretty good range of plants, and the same variety can be purchased at different stages of its growth, from juvenile through to fully grown. Further afield will offer more specialized nursery stock for something a little different. The gregarious practice of swapping cuttings still occurs but you can just as easily establish your own patch with diversity by visiting an otherwise anonymous nursery retailer. But you do not even have to do that.

A phone call to one of the new breed of professional garden designers now servicing those of means will deliver you layout, lawn, plants, planters, the works, and suddenly you will have an instant garden without having to turn a sod yourself. For another financial outlay, someone who only has a first name, perhaps 'Jim', can do the ongoing care and 
cultivation. Indeed, you need never go out into the garden at all for anything other than entertainment and boastful display. One can only surmise what the ' $n$ th' degree of this trend will become, perhaps headgear that transports you into a Holodeck garden with optional bouquet simulation? Whatever, this trend is symptomatic of the broader phenomenon of the experience economy in which cultural activities are disaggregated into units of consumption. In this specific instance, the complexity of gardening is reduced to simply another (fashionable) site to be experienced or exhibited as an object of possession.

However, this is but one avenue of contemporary gardening. Down a different allée, we can observe the continuing popularity of the actual practice of establishing and tilling one's own patch in contemporary societies. The popularity of practical gardening may even be on the increase judging by the proliferation of gardening publications, the number of gardening columns and programmes, and the array of businesses servicing garden-making. There are also elements of consumption and display here, yet these appear to be secondary to a more fundamental impulse of place-making and place-use.

Unsurprisingly, Seddon offers some thoughts on this gardening impulse. He notes that what is articulated in and through our gardening efforts can be as simple as a fashion statement and as complex as an unreflected moment of our native culture. Seddon thus suggests that as we attempt to make sense of our gardening it is good idea to be conscious of the fact that sometimes 'we are acting as a ventriloquist's dummy' (Seddon, 1997: 146). Gardens are rich sites of meaning that can unfold behind our backs as much as they grow before our eyes. Taking a few steps back can help us develop a more nuanced view of our gardening. Far from generating a haughty distance, this interpretative strategy warms Seddon to elaborate on the fecundity of gardening action:

Perhaps the most important benefit of gardening is the freedom to establish and define one's own territory, vital for many animals in creating confidence in the security of the immediate environment. In our own garden we can make our own decisions, give free rein to our creative impulses, make our own mistakes, and learn from them, change our minds, watch and observe the consequences of our actions, gain some insight into natural processes, and tie ourselves to the rhythm of the seasons. (Seddon, 1997: 164)

Understood in these terms, gardening can offer more than just a little piece of solitude, more than a place in which we attempt to exercise some control in a world that otherwise seems to be beyond our grasp. Seddon is making bigger claims for the gardening experience: it proffers the possibility that some courses of action could be otherwise; it makes us curious about the origins and history of plant cultivation and adaptation, about different geographical locations and climatic conditions. Seddon finds it inconceivable that a real gardener could lose interest in life. Indeed, he regards gardening not as a retreat but as an entrée into the world: 'In one's own garden, one is in contact with the whole globe, both cognitively and imaginatively'. For Seddon himself, garden-making in different locations over the years has been a journey and a personal evolution, a process of learning to live with the territory (Seddon, 1997: 165).

The capacity of people to engage with gardening in the way that Seddon has done is obviously varied. Nonetheless we can consider his idea of the garden, at least in normative terms, as a realm of possibility without prescription or proscription. In the face of the contemporary malaise of cultural simultanagnosia, it is certainly suggestive that our opportunities to be 'human actors in earthly places' are not as exhausted as the hyper-jive on cyberspace tries to insist (cf. Cairncross, 1998). This is possibly one of the key reasons why there is an ongoing enthusiasm for garden-making in the contemporary context. It enables us to engage with our ecocultural world, to experience some sense of an integrative 
overview of this world and our place in it.

But more can be drawn from the garden idea than simply presenting a counter model of experience. This alludes to the third trend in contemporary gardening that can be headlined, namely, the developments in the scholarly study of gardens over the last 25 to 30 years. Of particular note in this field is the marked shift from description to critical explanation, especially in the area of garden history.

In general, the garden has become a popular subject for academic analysis in a number of disciplinary fields. Unfortunately for the complexity of the garden idea, many of these studies lay special claims on garden-making, claims that are preempted by agendas already set within particular disciplinary specialities. Perhaps the most oft-repeated and clichéd manoeuvre exemplifying this practice is the paradigmatic collapsing of the diversity and complexity of the garden idea into a singular power technics typified by the gardens at Versailles. Aside from other problems, the garden idea is here rendered unilaterally into a power ontology that is itself open to question (Crozier, 1996). Fortunately, in recent decades there has also emerged a distinct field of research that takes the idea of the garden seriously. This approach has as its prime focus the conceptualization and practice of gardening, the critical analysis of historical and extant gardens and landscapes, and a commitment to the development of theoretically sophisticated and empirically informed perspectives on the garden. Seddon can be cited as an active contributor to this growing field of investigation

A number of seminal studies on English garden history appeared in the postwar period, but these tended to remain highly descriptive, content to simply reiterate a number of explanatory truisms that had their ultimate origins in the late 18th century in Horace Walpole's history of modern gardening (Walpole, 1771/1982). Walpole's history remains an important document for critical historical analysis but is conceptually limited, especially given its whiggish myopia. The historical and theoretical revision of these truisms began around the middle of the 1970s. This gathered significant momentum by the mid-1980s and was marked by the reissuing of numerous historical treatises on gardens, the publication of new periodicals like the Journal of Garden History and the appearance of several conceptually sharp studies on historical and more contemporary garden themes.

From one angle, the emergence of this distinctive field of analysis can be accounted for as a specific case of the more general phenomenon of intensified cultural reflexivity that has arisen in the informational age. Yet it can equally be linked to the new waves of interest in gardens and gardening that blossomed in the 1980s, some of the reasons for which we have already rehearsed vis-à-vis simultanagnosia and place-making. There is also another dimension that needs to be incorporated into this explanatory constellation, a dimension that is partially a consequence of the other two but has quite significant implications that potentially extend beyond gardening theorization per se. This refers to some contemporary research claims about the anthropological status of place-making - landscape architecture with gardening as the most concentrated form of this activity.

One writer who has pursued and promoted theoretical innovation in this area is John Dixon Hunt. Shifting from the literary study of landscape in the early 1970s, Hunt has become a leading garden scholar generating a number of significant historical and theoretical studies on gardening. He directly confronts the issue of garden theorization in his recent study entitled Greater Perfections: the Practice of Garden Theory (2000). Several key arguments advanced in this work are relevant to the present discussion.

Hunt is concerned to demarcate out a distinctive field of inquiry for landscape architecture and garden studies. While there is a wide range of cognate disciplines that deal with matters pertinent to place-making and place-usage, the subject of landscape 
architecture has no distinct intellectual tradition of its own, no specific history, theory or even practice of its own. Despite the voluminous amount that has been written on gardens, Hunt maintains that 'none of it satisfies even the basic requirement of a theoretical position' (2000: 7). Various elements for such theorization have been articulated or implied but without the systematic shift into adequate generalization. Hunt thus challenges garden theorists to invent the subject anew, to generate the conceptual reinforcement necessary for landscape architecture practice. Rather than taking one's primary orientation from the likes of Lacan, Derrida or Foucault, the garden theorist must discover the grounds for an adequate theory within the activities of garden art and landscape architecture themselves. Hunt takes up this programmatic challenge and ventures some initial theorems or theses drawing on the work of Augustin Berque on place-making and sense of place (see Berque, 1998). He also utilizes the work of George Seddon and J. B. Jackson.

The crucial theorem here is the proposition that landscape architecture is a fundamental mode of human expression and experience' (Hunt, 2000: 8). Historically, place-making can be detected from the earliest manifestations of human life on earth. Although there are many different cultural forms of place-making across different times and places, the activity itself can nonetheless be understood as an 'art of milieu', to use Berque's term.

There are two facets to Berque's notion of milieu. First, the creation of landscape, in whatever form, is not simply a question of landscape, but the 'mediation of landscape'. This conveys the sense that we are literally in the middle and surrounded by our 'milieu'. But it is us, ourselves and our fellow human beings, who have constituted and continue to modify these surroundings. The second aspect of milieu is the understanding that landscapes are the combination of the place-made and the place-maker or place-user. In effect, subject and object are indiscernible elements of the total landscape. This is the case no matter whether we are concerned with the making or the experiencing of landscapes well after their creation. Landscapes become landscapes through the creative interaction of a perceiving subject and an object perceived. Thus the notion of milieu gives full weight to the facts of each physical site while simultaneously admitting the modifying or mediating input of the human subject.

Once understood in these terms, Hunt suggests that landscape architecture rehearses a central modern dilemma: 'how to endow the world with value, without falling into the error of arguing either that value adheres in the world or that the world is devoid of value' (Hunt, 2000: 9). In terms of landscape, this dilemma is contiguous with Seddon's critical concerns about the idea of sense of place. The notion of milieu offers a conceptual passage through the dilemma. In place-making or place-visiting, humans bring along an array of cultural, social and historical resources that have made them into human subjects. As individuals they also bring into play their various tastes, memories and what Berque calls 'dispositions of the moment'. Something like a sense of place gathers where this human complexity meets an ever-changing object. Place-making involves the drawing together of unmediated elements and processes of the physical world with human art and culture which mediates these 'natural' elements and processes. Hunt notes that this combination is almost unique to human place-making, with the possible exceptions of human dance and body art. He also ponders if this is the reason "why human beings alone among all the animals create gardens' (Hunt, 2000: 10), and contra the instinctual behaviour of, say, the bowerbird.

Hunt maintains that these types of consideration can help to define both the challenges and problems of practising garden theory. He thus frames the research programme for garden studies as follows: 
It seems to me that we need what might be provisionally understood as an anthropology of the garden. This would explore the many cultural versions of the idea or essence of the garden, what (borrowing from Berque) we could call the different 'symbolic performances of milieu or médiance'. (Hunt, 2000: 13)

This most certainly seems to offer all sorts of possibilities for research into the diversity and complexity of place-making and gardening in particular. But this can also be turned around on itself in order to attempt an explanation for why Hunt's petition for an anthropology of the garden might be seen as a sign of our times. Put another way, could garden theory help us to understand why calls for a distinct discipline of garden studies has arisen at this time? Could it even throw additional light on the more general furor hortensis of recent decades?

We can recall Melucci's observation that planetary society is totally interconnected by its capacity for intervening on its environment and on social life itself. This is a world that induces the cultural malaise of simultanagnosia. But paradoxically, it is also a world in which the essential character of time and space is a cultural artefact constituted within everyday social relationships. If we draw this across into garden theory, it has profound implications for our own 'symbolic performances of milieu.' It seems that Berque has already executed a manoeuvre like this, even if in a slightly different manner. He describes current times as the 'era of the planetary garden.' He is also curious about the contemporary interest in landscape, in 'paysage', and offers the following explanation:

.. . the rise to prominence of the theme of landscape in our society is nothing but the taking into account, by the human actor who modifies his or her environment, of the very subjecthood of his or her own tastes. Contemporary territoriality has become performance by the subject itself: we put ourselves into shape in the landscape that we set up. ... It is by way of conscious engagement, not by some sort of karmic or Heideggerian destiny, that today the subject (Being), by way of landscape, makes itself into chora or basho; that is land of oneself. (Berque, 1998: 114-16)

In the garden of one's own making, persona emerges through the playing out of subject and object in place. Tending the garden is perhaps now no longer so much a place to get lost in but to get found in. Therefore, as contemporary experience tends to differentiate into discrete modules, there is paradoxically also a tendency to reengage with the ecocultural world in the form of place-making, in symbolic performances of milieu. In short, in a world of disaggregated and fragmented experience, in a world of 'nonplaces' (Marc Augé), a new sense of place emerges.

\section{EPILOGUE}

This is perhaps a circuitous way to propose that George Seddon, the gardener, is on to something. He can be characterized as thoroughly 'aftermodern', so to speak. He has no problem with mobility and indeed loves to travel. But unlike the PoMo cyberset, Seddon is a traveller with a grounded sense of place. He is a happy, or more precisely, a 'settled' traveller who culturally invests in places, and as a result has some sense of his milieu and a bit of an idea about himself. Like his Fremantle garden, his work is an oasis, a place that continually refreshes on return visits.

Michael Crozier teaches Political Science at Melbourne University. Current areas of research include political communication, network society, history and theory of the social 
sciences, and garden theory. Recent publications include: The Left in Search of a Center (1996) with Peter Murphy; Australian Politics in the Global Era (1998) with Ann Capling and Mark Considine; and After the Garden? (South Atlantic Quarterly, 1999). Address: Department of Political Science, University of Melbourne, Victoria 3010, Australia. [email: mcrozier@unimelb.edu.au]

\section{References}

Berque, A. (1998) 'Landscape and Immanence', Thesis Eleven 54: 106-16.

Cairncross, F. (1998) The Death of Distance: How the Communications

Revolution will Change our Lives. London: Orion Business. Castells, M. (2000)

'Materials for an Exploratory Theory of the Network Society', British Journal

of Sociology 52/1: 5-24.

Crozier, M. (1996), 'Inter putatorem et vastitatem: The ambivalences of the Garden Metaphor in Modernity', in M. Crozier and P. Murphy (eds) The Left in Search of A Center. Urbana: University of Illinois Press.

Grüsser, O-J. and Landis, T. (1991) Visual Agnosias and Other Disturbances of Visual Perception and Cognition. London: Macmillan.

Hunt, J. D. (1986) Garden and Grove: The Italian Renaissance Garden in the English Imagination 1600-1750. London: Dent.

Hunt, J. D. (1991) 'The Garden as Cultural Object', in S. Wrede and W. H. Adams (eds) Denatured Visions: Landscape and Culture in the Twentieth Century. New York: Museum of Modern Art.

Hunt, J. D. (2000) Greater Perfections: the Practice of Garden Theory. London: Thames \& Hudson.

Melucci, A. (1996) The Playing Self: Person and Meaning in the Planetary Society. Cambridge: Cambridge University Press.

Rifkin, J. (2000) The Age of Access: The New Culture of Hypercapitalism, Where All of Life is a Paid-for Experience. New York: Tarcher/Putnam.

Seddon, G. (1997) Landprints: Reflections on Place and Landscape. Cambridge: Cambridge University Press.

Sennett, R. (2000) 'Street and Office: Two Sources of Identity', in W. Hutton and A. Giddens (eds) On the Edge: Living with Global Capitalism. London: Jonathan Cape.

Strong, R. (1979) The Renaissance Garden in England. London: Thames \& Hudson.

Van Dijk, J. (1999) Network Society: Social Aspects of New Media. London: Sage.

Walpole, H. (1771/1982) The History of Modern Gardening. New York: Garland.

Wellman, B. (2001) The Persistence and Transformation of Community: From Neigh bourhood Groups to Social Networks. Toronto: Wellman Associates/Report to the Law Commission of Canada. 


\section{University Library}

\section{- M M N E R VA A gateway to Melbourne's research publications}

Minerva Access is the Institutional Repository of The University of Melbourne

Author/s:

Crozier, M

Title:

Simultanagnosia, Sense of Place and the Garden Idea

Date:

2003-01-01

Citation:

Crozier, M. (2003). Simultanagnosia, Sense of Place and the Garden Idea. Thesis Eleven, 74 (1), pp.76-88. https://doi.org/10.1177/07255136030741006.

Publication Status:

Published

Persistent Link:

http://hdl.handle.net/11343/34421 